\title{
NO CENÁRIO DE SALA DE AULA, DUAS PERSPECTIVAS PARA SE DISCUTIR O ERRO EM LÍNGUA PORTUGUESA
}

\author{
Lourdes Terezinha Graebin Parise \\ Prof ${ }^{\mathrm{a}}$ de Língua Inglesa do Cefet-PR, unidade de Patoss Branco. Mestranda \\ em Educação (FACIPAL/CPEA)
}

Maria Ceres Pereira

Prof ${ }^{a}$ da UNIOESTE - Doutora em Lingüística Aplicada.

\begin{abstract}
Resumo: As pesquisas em sala de aula na região sudoeste do Paraná encontram-se em estágio inicial, contudo, já aparecem indícios de similaridades e distanciamentos entre o que ocorre em termos do que é "corrigir" o aluno em situação de sala de aula. Vários são os fatores pontuados e outros que passam invisíveis aos olhos do(a) professor(a) em interação com seus alunos no momento da correção. Assim, neste trabalho, busca-se focalizar dois momentos com professoras diferentes em cenários geograficamente distantes de sala de aula. A partir de excertos, procura-se discutir como as mesmas lidam com questões inerentes ao ato de corrigir. Procura-se, nesta perspectiva, abordar como corrigem? O que corrigem? De que forma o fazem? As comparações foram possíveis graças ao envolvimento em campo de pesquisadores em formação.
\end{abstract}

Palavras-chave: pesquisa, etnografia, sala de aula, interação/correção

\section{A Título de Apresentação}

A sala de aula tem sido um cenário amplamente focalizado e refletido em trabalhos acadêmicos. Neste ano, particularmente, um trabalho relevante foi compilado pelas professoras: Cox, M.I. e ASSIS-PETERSON, A. Através do qual, as autoras trazem artigos de vários autores focalizando a sala de aula. As perspectivas são várias muito embora, a tônica se volte para os aspectos interacionais, seus resultados e conseqüências aos aprendizes. Entretanto, muito embora diversos trabalhos partam deste lócus, há sempre o que dizer e inovar neste campo fértil e peculiar de estudo.

No prefácio do livro referido anteriormente, Erickson: 2001 afirma que a falsa idéia de que conhecemos tudo sobre sala de aula, cega-nos a visão e, 
assim, não percebemos a peculiaridade que faz a cultura de cada sala de aula algo único, a torna igualmente única, original e diferente de todas as outras salas de aula.

Sem deixar estas questões de lado, propõe-se neste artigo, discutir cenários de sala de aula buscando desvendar suas especificidades. Trata-se de salas diferentes, igualmente localizadas em contextos regionais distintos. A primeira se localiza na região sudoeste do Paraná, a segunda na região oestei[i]. Ambas, entretanto, têm como foco as séries iniciais do ensino fundamental sendo este o ponto que as aproximam.

No caso da sala de aula do Sudoeste, buscou-se a questão da correção de uma redação de uma menina. A professora parte de um texto escrito para, então, corrigir alguns elementos gramaticais. Para a análise não se tem 0 aspecto interacional da sala de aula para se discutir aspectos inerentes a negociação de sentido. No outro caso, a professora usa a letra de uma música e a própria música como insumo para sua aula (gravada). Desta forma têm-se elementos para abordar a interação que ocorre entre professora e seus alunos. Há momentos de leitura e de ilustração no caderno a partir do texto lido e cantado pelos alunos.

\section{Palavras Iniciais}

Durante muitos anos, por razões históricas, sociais e políticas, a língua nos foi apresentada como um fato único e homogêneo, com base apenas nas regras da gramática normativa ou da gramática tradicional. A escola, em muitos cenários, ainda passa a noção de que a língua se constitui em um padrão único - a variedade padrão, e tudo o que se afasta desse padrão, é considerado errado, sempre visto como um desvio de uma norma pronta e acabada. Podemos observar este fato em muitos procedimentos metodológicos, quando do ensino da Língua Portuguesa tanto em escolas urbanas quanto as que estão nos limites das áreas rurais/urbanas.

Entretanto, pergunta-se: o que é esta norma pronta e acabada? Em resposta, pode-se partir daquela estabelecida e contemplada pela escola. Mas e a outras? Aquela que dita os padrões de certo e errado nas comunidades de 
fala? Nesta perspectiva, vale o exemplo da tese de Pereira: 1999 em que focaliza uma comunidade rural bilíngüe alemão/brasileiro/português. Em suma, os moradores daquela comunidade, falavam alemão ao que diziam "não ser o alemão de verdade", nas interações com as pessoas amigas e da família. Era, portanto, a língua do coração. Com os que não falavam alemão, usavam, o "brasileiro", marcado por traços que o diferiam do português da escola. $O$ brasileiro era, portanto, a língua da solidariedade. $\mathrm{Na}$ escola, as crianças buscavam acesso ao português do livro didático. Apesar desta complexidade lingüística, as pessoas tinham critérios para julgar o bom ou o mal falante do alemão, por exemplo, era permitido usar palavras do português deveria ser mínima. Era necessário, igualmente, fluência, desembaraço ao falar tal língua. Esta era uma norma acordada pela comunidade. Outra norma, era aplicada ao brasileiro, por exemplo, as pessoas deviam usar uma variedade marcadamente rural e traços descontínuos que, para Bortoni in mímeo, seria uma especificidade de uma comunidade de fala. No caso do estudo de Pereira, os falantes usavam o verbo ganhar com sentidos diversos. Podendo significar: sofrer, sentir, receber - minha avó ganhou um ataque= sofrer; nós ganhamo visita =recebemos; minha prima ganhou dor de barriga= sentiu. Pode-se abordar por estas questões, que a norma lingüística não pode ser assim tratada. Ou seja, não é algo pronto, acabado. Antes, é algo em construção e isto ocorre na interação entre os usuários da língua. Por outro lado, o aprendiz deve ser sensibilizado no sentido de perceber as variedades lingüísticas e a perceber o que provoca o uso de uma ou outra variedade.

Em tese, aquela variedade contemplada pela escola é que dará, aos seus usuários, melhores acessos sociais. E neste sentido, a escola precisa fazer o máximo esforço para garantir que o aprendiz se aproprie de tal variedade. E deve fazer isto sem provocar o sentimento de inferioridade, reforçando o estigma de que é falante de uma variedade de menor prestígio social e, por isso, é menos inteligente, é feio e inculto. Soares:1996 traz algumas considerações significativas em Linguagem e Escola a partir de teorias que permitiram a geração de imagens negativas em relação àqueles que chegam à escola ou usando uma variedade lingüística desprestigiada, ou 
trazendo um descompasso entre a cultura de casa e a cultura da escola, ou cujos acessos aos materiais de leitura e escrita tenham sido parcos.

Tendo em vista estas questões presentes é que se prossegue para a análise das salas de aula.

\section{As sutilezas do erro, o que é erro ?}

Ao se olhar para as amostras que estarão compondo este momento de análise, há que se ter três questões em mente: 1) o professor corrige palavras escritas corretamente e devidamente acentuadas ou não; 2) o professor não corrige determinados erros de escrita e 3) como, na sala de aula, a negociação leva à correção a partir da interação professor/aluno(s)/texto base.

No primeiro caso ocorre o seguinte:

\section{Prima Vera}

A prima vera começa hoje dia 23 de setembro. A prima vera quer diser dia das, flores prima vera quando todas as crianças dultos, gostam de fazer aumenagem as flores.

Eu notei que na prima vera todas as flores estão mais bonitas as árvores aflorecem ficam tão bonitas as pêras as flores branca. Pêssego as flores rosas e rosa se abre fica tão bonitas, a flor bonita que só aflorece na primavera é a margarida essa sim é uma flor bonita sabe: por que é o nome de minha mãe tem tantos nomes de pesso com o nome das flores: tem Margarida, Rosa Rozinha Jasmin e vários outros nomes lindos.

É um pouco que eu sei da Prima Vera. 
Há nitidamente um trocadilho entre a estação do ano e a alusão a pessoas cujos nomes são nomes de flores, no caso, similar ao da estação dano. A aluna, somente no final de sua redação, após relacionar os nomes que ela conhecia e que são nomes de flores, escreveu: Prima Vera em separado e com letra maiúscula. As demais ocorrências desta palavra, a aluna separou embora usando regularmente, a letra minúscula. Certamente, não se tratando de nome de pessoa. Nesse sentido, é interessante que o professor observe o instante em que a criança explicita por escrito, a sua preocupação com determinado aspecto formal ou semântico da linguagem. Desta forma, o professor sensível percebe a preocupação da criança, na origem do problema para a qual passa a buscar uma solução. A criança, certamente, estará trabalhando e construindo as hipóteses para seu fazer.

Neste caso da redação acima, a menina não estabeleceu a devida concordância em alguns pontos como em: a rosa se abre e fica tão bonitas; as flores branca. Muito provavelmente, porque aplicou uma regra de sua fala na qual basta marcar o plural em um só elemento para entender que toda a oração está no plural. E esta regra é partilhada pelos falantes de português como primeira língua de uma maneira ampla como se poderá observar nos excertos de sala de aula. No tocante a não/correção por parte da professora, esta não foi muito rigorosa neste aspecto. Isto porque, a marcação em um elemento somente para o plural de uma oração, na regra do uso oral, estaria posta no primeiro segmento da oração. Ou seja, seria natural uma construção como realizada pela menina em: as flores branca. No outro exemplo, a menina marcou o plural somente no final da oração: a rosa se abre e fica bonitas. Quando natural seria: As rosas...Mas a professora não olha para estes erros, preocupa-se com aqueles de segmentação como nos casos de: dultos por adultos; pesso por pessoa. Igualmente, a correção não se dá em relação a pontuação. Algumas análises têm mostrado que, em alguns momentos, nas séries iniciais a preocupação ocorre em relação à escrita de forma a criança se 
colocar mais à vontade com este mecanismo da escola. Após entram as correções acerca de problemas referentes a segmentação, organização estrutural, reelaboração gramatical etc... Esta prática não é particular de um professor, parece ser extensiva e partilhada por outros professores em outros cenários de sala de aula conforme se pode observar a seguir:

Ao corrigir trabalho escrito, ela ( a professora) diz observar as frases $e$ as respostas às questões e não prestar muita atenção à ortografia; em relação à escrita (grifo meu), particularmente, ela não atribui qualquer nota, uma vez que é feita para expressar as idéias e não para ser alvo de cobrança de gramática e ortografia. (Hornberger,N.H. 2001:36-37)

No caso da redação da aluna focalizada a partir do texto anteriormente apresentado, parece ser o caso de escrita criativa, embora, a professora tenha sugerido o tema. Tanto a criança poderia, ao escrever, "brincar" um pouco com o trocadilho entre o nome prima Vera quanto com o substantivo primavera. Neste sentido, certamente, a preocupação da professora não estivesse se voltando para a escrita, enquanto objeto de correção, mas de levar a criança a familiarizar-se com este processo. Razão porque, provavelmente, a professora não estivesse preocupada com a correção de itens gramaticais.

No caso das frases: as árvores aflorecem e a flor bonita que só aflorece na... são marcas de uma norma lingüística partilhada pelos falantes da variedade popular. Incorreções como esta, na escrita, denotam o reflexo do oral na escrita e, por vezes, podem passar invisíveis aos olhos do professor por ser este, usuário de tal variedade. Trata-se aqui de uma suposição que será retomada logo após a abordagem de algumas situações de sala de aula a partir da interação professora/alunos/texto de leitura.

Os excertos a seguir são recortes de uma aula de leituraii[ii] em que $\mathrm{P} 1$ é a professora regente da sala; J é um dos alunos e T está sendo usado para quando todos falam ao mesmo tempo. 
1. P1 - Aqui é uma história, uma história imaginária. E houve uma festa nu céu. I a tartariguinha viajou na orelha du elefanti.

2. J-Du elefanti

3. P1 - Isso de lá aconteceu u quê?

4. T-Caiu

5. P1 - E o que São Pedro feiz?

6. J. Barreu! Depois!

7. P1 - Varreu! Pra ela cair, né? I ela caiu i si quebrou!

8. J. - ele colo ela cum super bondi acontece?

9. P1 - O pai du céu lá pego i colo! Será qui isso é pussível

10. T-Não!

11. (...) $P 1$ - Si junto bastante caquinho, qui quebro i feiz caquinho, quer dizer qui os cacu era piqueno, da tartaruguinha.

12. J. - Nóis vai desenha agora?

13. 13. P1 - Agora, nóis vamo ilustra a história. Vocês vão recebe as folha qui vai te a musiquinha com os quadro, e nóis vamo ilustra...

Ao se olhar para o fragmento da aula acima, percebe-se um grau acentuado de interação entre professora e alunos em que, a professora faz a correção de algumas entradas do aluno $\mathrm{J}$ em outras ocasiões ela não corrige. Por exemplo, na linha 5, a professora pergunta o que São Pedro fez, o aluno J responde prontamente na linha 6 - barreu. A correção ocorre imediatamente sem que a professora diga expressamente que o aluno errou. Ela diz a palavra certa, na linha 7 e prossegue sua fala. Na seqüência, linha 6 , o aluno $\mathrm{J}$ responde usando uma forma própria da modalidade oral e a professora não o corrige como o fizera no caso de "barreu". 
Na linha 11 a professora parafraseia uma parte da história e, ao fazêlo, não expressa uma fala monitorada cf. Bortoni: 2001, usa a variedade própria de sua comunidade de fala e que parece ser a mesma partilhada pelos seus alunos. Não há concordâncias postas dentro dos preceitos gramaticais como em: quer dizer qui os caco era pequeno, da tartaruguinha. Quebro, formô os caquinho. Nas regras da fala, conforme já fora dito, bastaria marcar o plural no primeiro segmento da oração e isto permitiria interpretar que toda a oração estivesse no plural. Esse tipo de correção, certamente, a professora fará quando os alunos estiverem escrevendo. Neste ponto, pode-se voltar ao texto posto no início da análise - primavera. Em tal redação da aluna, não há o estabelecimento da concordância em: as flores branca ao que a professora não corrige. O caso parece similar entre o que acontece na fala desta professora o que parece confirmar o que ocorre entre o contínuo oral/escrito vs. o pertencimento a uma comunidade de fala em cuja a norma é partilhada.

Contudo, na sequiência, quando professora e alunos reconstroem a história, desenhando-a em seus cadernos, a professora é cuidadosa porque, certamente, está presa ao texto escrito da historinha. Vejamos:

1. P1 - Agora, nóis vamo ilustra a história. Vocês vão recebe as folha qui tem a musiquinha com os quadrinho e nóis vamo ilustra o que...

2. (...) Quando a festa terminou a bicharada si mandou! Quem viu a tartaruguinha? Quem viu? Lá do céu ela caiu. São Pedro (...) a pobrezinha se esqueceu. Ela disse: eu mi quebrei toda(...)

3. P1 - Como é qui vou fazer

4. Como é qui vou fazer, pai do céu? Como vou viver agora? Pai do céu é quem?

5. T-Jesus!

6. P1 - Jesus ou é Deus!

7. T-Deus!

8. P1 - Juntou os caquinhos, pai do céu juntou os caquinhos, colou, i mais bunita ela ficou! 
Se olharmos para a primeira linha e compararmos com a linha 8 , poderemos perceber marcas da variedade estilística da professora. E isto parece se relacionar a função do uso na relação com seus alunos. Exemplo está, na primeira linha, em que está falando com os alunos, orientando-os para o que farão na seqüência em relação à história. Na oitava linha, ela está lendo e todas as marcas de concordância previstas pela orientação gramatical, estão presentes. Alguns processos fonológicos próprios da fala como o emprego do $i$ por e; o por u como em bunita, são usados na leitura e isto mostra, de certa forma, que a leitura não é um processo "tão isento" e que, ao ler, o leitor leva suas marcas valendo-se das regras da fala em muitas das vezes, deixando de lado, a propriedade do texto escrito. Que o leitor ao fazer uma leitura, principalmente em voz alta, leva a variação estilística que Ihe é própria, denotadora de marcas regionais para sua leitura, assim imprimindo traços prosódicos, fazendo harmonizações vocálicas etc... Enfim, poderá evidenciar de que região este leitor é oriundo. A que comunidade de fala pertence etc... Em contrapartida, todo o segmento da linha 2, a fala da professora não é monitorada, certamente porque ela está buscando maior envolvimento com seus alunos de forma a leva-los a participar ativamente da atividade proposta.

Para encerrar este momento de análise, vale trazer, finalmente, um último recorte de sala de aula com a mesma professora, porém, no momento de realização de exercício gramatical. Tal exercício é ainda focalizado a partir do mesmo texto da historinha.

1. P1 - Aonde qui ela foi? O que ela foi faze, né? Nós vamos inscreve nu gerau sobri a música. O que qui ta se falandu, né? Retire du textu palavras monossílabas. Comu qui é palavras monossílaba?

2. T - uma sílaba

3. P1 - só tem uma...

4. J. - palavra!

5. T. - sílaba! (em coro, todos os alunos juntos)

6. P1 - sílaba. Dissílaba?

7. T-duas 
8. P1 - Trissílaba?

9. T-trêis

10. P1 - Polissílaba?

11. T-quatro ou mais...

Embora a professora neste momento esteja trabalhando aspectos gramaticais, sua fala com os alunos não se pauta pela correção gramatical. Dizendo de outra forma, a questão da concordância não é observada como em: nós vamo iscrevê.. comu é palavras monossílaba! Mas, apesar deste "descuido", a professora antes de partir para o exercício proposto pelo livro, retoma os conceitos a serem trabalhados. Busca assegurar-se de que seus alunos façam a tarefa sabendo o que está "em jogo". Para testar o conhecimento de seus alunos a professora faz perguntas sobre o ponto e a interação é muito produtiva, pois todos os alunos se envolvem respondendo suas perguntas satisfatoriamente.

$\mathrm{Na}$ linha 4, entretanto, o aluno $\mathrm{J}$ responde uma das perguntas de forma errada, porém, é corrigido pelos colegas que the dão, em coro, a resposta correta - linha 5. Após a resposta em coro, a professora reforça repetindo a forma correta, prossegue formulando outra questão.

Após este momento, os alunos passam a trabalhar sozinhos e a professora circula entre as carteiras conferindo os cadernos dos alunos. Vai até a carteira do aluno $\mathrm{J}$, que the dera a resposta incorreta e discute com ele $\mathrm{o}$ encaminhamento do exercício, ocorrendo a seguinte seqüência:

Olha aqui. Num é uma sílaba só? Lá. Num é uma sílaba só? Num é uma sílaba só? Aqui, ó.Olha aqui. Monossílaba, que só tenha só uma sílaba. Vamo iscrevê aqui os monossílabo. Vamo iscrevendu, pega seu lápis. Olha aqui. Num é uma sílaba só, um "lá", um "no" ? Coloca uma vírgula pra separa. Ou um traço. Agora com duas sílaba (...) 
A professora procurou explicar, particularmente, ao aluno $\mathrm{J}$ o que significam palavras monossílabas e dissílabas a partir da noção de sílaba. Esta noção de caráter fonológico, exige conhecimento técnico lingüístico da língua cf Cagliari:1995 e isto, muitas vezes, é insípido para o professor. Desta maneira, a explicação fica um pouco vazia como se pôde ver acima. A sala de aula, como se pôde ver até então, é um laboratório interessante de pesquisa. Entretanto, parece que o próprio professor deve ser alguém, no mínimo reflexivo sobre sua prática. Senão, pesquisador de seu fazer didático pedagógico. Outras questões seriam relevantes neste trabalho, contudo, deixa em aberto outros espaços para discussão.

\section{Palavras Finais}

Buscou-se com este trabalho, a tarefa de uma discussão acerca de duas possibilidades ao erro de escrita nas séries iniciais. Para tanto, estabeleceram-se diálogos entre duas escolas em cenários regionais distintos. Na primeira, a professora propôs uma atividade de redação que, de certa forma, pressupõe uma escrita criativa. Na segunda, a professora se valeu de um texto base de uma historinha e várias atividades se desencadeiam.

A forma de lidar com a questão do erro de escrita é diferente em ambos os casos. Assim, a primeira professora marca o texto da aluna de formas diferentes. Em alguns momentos faz um quadrado onde a aluna escreve prima vera como palavras distintas. Marca os erros de segmentação, mas não o faz onde a concordância não está bem estabelecida.

A segunda professora, constrói com as crianças, a partir da interação, praticamente todas as atividades propostas. Em termos de modelos lingüísticos, a mesma não pratica uma fala cuidada/elaborada. Há momentos flagrantes em que a concordância não se estabelece. Entretanto, quando está mais presa ao livro, seu estilo é mais monitorado.

Apesar das diferenças em termos de postura das duas professoras, parece haver um ponto comum no que tange ao que corrigem ou não. Ambas não se "preocupam" tanto com a concordância a ser seguida nos eventos de sala de aula. Contudo, a professora dois, parece praticar uma pedagogia culturalmente sensível cf. Erickson:1987 uma vez que, apesar de não explicitar um conhecimento técnico da língua de forma mais própria, tenta tornar claro 
para o aluno $\mathrm{J}$ o conceito que está em questão no exercício. A aparente não preocupação das professoras no que diz respeito a ausência de concordância tanto na fala quanto na correção dos exercícios, provavelmente, se liguem aos usos que fazem em suas comunidades de fala. Desta forma, estas questões se tornam invisíveis, em conseqüência, não corrigidas por ambas.

Este trabalho faz parte de uma pesquisa em andamento conforme nota de fim, desta forma, não se apresenta aqui uma conclusão que se reporta a um caráter mais definitivo. $\mathrm{O}$ trabalho está em fase de análise geral dos registros.

Referências Bibliográficas

1. BORTONI, S. M. - MÓDULO I Organização do Trabalho Pedagógico. Universidade de Brasília. 2001

2. CAGLIARI, L. C. Alfabetização e Lingüística. Editora Scipione. São Paulo. 1995

3. ERICKSON, F. Prefácio. In: COX, M.I. P. e PETERSON-ASSIS, A (orgs.) Cena de Sala de Aula. Mercado de Letras. Campinas/SP 2001

4. HORnBerger, N. Criando Contextos Eficazes de Aprendizagem para o Letramento Bilíngüe. Tradução das organizadoras - COX, M. I. P. e PETERSON-ASSIS, A - Cena de Sala de Aula. Mercado de Letras. Campinas/ SP 2001

5. PEREIRA, M. C. No Oeste Paranaense: Língua e Aprendizagem em Contexto Sociolingüísticamente Complexo. Projeto institucional apoiado pela Fundação Araucária. Unioeste/PR 2000 
6. PEREIRA, M. C. Naquela Comunidade Rural, os Adultos Falam "Alemão" e "Brasileiro". Na Escola, as Crianças Aprendem o Português. Por um Estudo do Continuo Oral/Escrito por Crianças de uma Classe Bisseriada. Tese de doutorado. IEL/UNICAMP. 1999

7. SOARES, M. Linguagem e Escola. Atica. São Paulo. 1996

i[i] Registros coletados pela Prof ${ }^{a}$ Ana Lívia Paese Zeczkowski, ligada ao grupo de pesquisa da $\operatorname{Prof}^{a} \operatorname{Dr}^{a}$ Maria Ceres Pereira, subsidiado pela Fundação Araucária.

ii[ii] Parte do corpus da pesquisa de sala de aula coletados pela Prof ${ }^{a}$ Ana Lívia Paese Zeckowski 